\title{
DO HOMO EMPREENDEDOR AO EMPREENDEDOR CONTEMPORÂNEO: EVOLUÇÃO DAS CARACTERÍSTICAS EMPREENDEDORAS DE 1848 A 2014
}

\section{RESUMO}

Este estudo procurou analisar a evolução das características empreendedoras partido dos estudos de Kuratko e Hodgetts (1995) sobre estas características de 1848 até 1982, buscando responder às questões sobre como elas evoluíram ao longo do tempo? que características se mantiveram? quais desapareceram? e quais surgiram? Para tanto, realizou-se uma pesquisa bibliográfica e bibliométrica de 1983 a 2014, complementando, ampliando e comparando os achados da pesquisa original. O levantamento bibliográfico se deu com base nas palavras-chave Empreendedor, Empreendedorismo, Características Empreendedoras, Atitudes Empreendedoras e Perfil Empreendedor e ocorreu a partir da seleção dos artigos publicados nos periódicos científicos nacionais mais bem classificados de acordo com o sistema Qualis, composto pela Revista de Administração de Empresas - RAE, pela Revista de Administração Contemporânea - RAC, pelos eventos científicos ENANPAD e EGEPE, e a base de dados EBSCO para acessar os periódicos científicos internacionais, a saber: Applied Financial Economics; Applied Economics Letters; Management Research Review; Journal of Product Innovation Management; European Management Journal; Service Industries Journal; International Journal of Entrepreneurship \& Innovation Management; Entrepreneurship: Theory \& Practice; Journal of International Entrepreneurship; Management Decision; International Small Business Journal. Este estudo, caracterizado como bibliométrico, revisou 288 artigos publicados por 341 autores e aponta em seus os resultados para um perfil empreendedor muito mais relacional, baseado mais em competências interpessoais e sociais e focado nas demandas do ambiente externo, do que o perfil auto centrado, soberano, autônomo e independente do empreendedor da primeira fase do século XX.

Palavras-chave: Características Empreendedoras; Perfil Empreendedor; Empreendedorismo.

\section{FROM THE HOMO ENTREPRENEUR TO THE CONTEMPORARY ENTREPRENEUR: THE EVOLUTION}

\section{OF THE ENTREPRENEURIAL CHARACTERISTICS FROM 1848 TO 2014}

\section{ABSTRACT}

The objective of this study was to analyze the evolution of the entrepreneurial characteristics parting from Kuratko and Hodgetts (1995) studies over these characteristics, from 1848 to 1982, seeking to respond to questions about how they evolved over time? which characteristics remained? which disappeared? and which emerged? To this end, a bibliographic and bibliometric research from 1983 to 2014 was carried, complementing, amplifying and comparing the findings of the original research. The bibliographic survey was made based on the keywords Entrepreneur, Entrepreneurship, Entrepreneurial Characteristics, Entrepreneurial Attitudes and Entrepreneur Profile, and from the selection of articles published in the highest rated national journals according to the Qualis system, composed by Revista de Administração de Empresas - RAE, the Revista de Administração Contemporânea - RAC, the scientific events ENANPAD and EGEPE, and the EBSCO data base in order to access international scientific journals, namely: Applied Financial Economics; Applied Economics Letters; Management Research Review; Journal of Product Innovation Management; European Management Journal; Service Industries Journal; International Journal of Entrepreneurship \& Innovation Management; Entrepreneurship: Theory \& Practice; Journal of International Entrepreneurship; Management Decision; International Small Business Journal. This study characterized as bibliometrics, reviewed 288 articles published by 341 authors and points on their results to a lot more relational entrepreneurial profile, based on interpersonal and social skills and focused more on the demands of the external environment than on the self-centered, sovereign, autonomous and independent entrepreneur profile of the first phase of the twentieth century.

Keywords: Entrepreneurial Characteristics; Entrepreneurial Profile; Entrepreneurship. 


\section{HOMO EMPRESARIO AL EMPRENDEDOR CONTEMPORÁNEO: LAS CARACTERÍSTICAS DE EVOLUCIÓN DE EMPRENDEDORES 18482014}

\section{RESUMEN}

Este estudio analiza la evolución de las características emprendedoras de los estudios del partido Kuratko y Hodgetts (1995) sobre estas características de 1848 a 1982, la búsqueda de respuestas a las preguntas sobre la forma en que evolucionaron a través del tiempo? características que permanecieron? que han desaparecido? y lo que surgió? Para ello, llevamos a cabo una investigación bibliográfica y bibliométrico 1983-2014, complementando, amplificar y comparar los resultados de una investigación original. El estudio de la literatura se hizo sobre la base de palabras clave del Emprendedor, Emprendimiento, características empresariales, Actitudes y Empresarial Perfil Emprendedor y se produjo a partir de la selección de artículos publicados en revistas científicas nacionales calificados de acuerdo con el sistema Qualis compuesta por la revista Administración de Empresas - RAE, el Diario de Gestión contemporáneo RAC, los eventos de la Ciencia y EnANPAD EGEPE, y la base de datos EBSCO acceder a revistas científicas internacionales, a saber: Aplicada Economía Financiera; Aplicadas Cartas Economía; Gestión de la Investigación de la opinión; Diario de Gestión de la Innovación de Productos; Diario Gestión Europea; Servicio de Industrias Diario; Revista Internacional de Emprendimiento e Innovación de Gestión; Emprendimiento: Teoría y Práctica; Revista Internacional de Emprendimiento; Decisión de Gestión; Revista Internacional de la Pequeña Empresa. Este estudio se caracteriza como la bibliometría, revisó 288 artículos publicados por autores y 341 puntos en sus resultados a un perfil empresarial más relacional, basado más en las habilidades interpersonales y sociales y se centró en las demandas del entorno externo, el perfil egocéntrico, soberano, autónomo e independiente del empresario de la primera fase del siglo $\mathrm{XX}$.

Palabras clave: Características Empresariales; Perfil Emprendedor; Emprendimiento.

\footnotetext{
${ }^{1}$ Doutor em Administração pela Universidade de São Paulo - USP. Professor e Pesquisador do Programa de Mestrado em Administração do IBMEC. Barsil. E-mail: fernandofilardi@gmail.com

${ }^{2}$ Mestrando em Administração pela Faculdade de Economia, Administração e Contabilidade da Universidade de São Paulo - FEA/USP. Brasil. E-mail: fdbarros@usp.br

3 Doutor em Administração pela Universidade de São Paulo - USP. Professor da Faculdade de Economia, Administração e Contabilidade da Universidade de São Paulo - FEA/USP. Brasil. E-mail: aafischm@usp.br
} 


\section{INTRODUÇÃO}

O Empreendedorismo vem consolidando sua importância no cenário acadêmico nacional nos últimos anos e este fenômeno fica evidenciado através do aumento do número de publicações e do crescimento do espaço destinado ao tema nos principais eventos de pesquisa e periódicos da área de administração.

Schumpeter (1950) preconizava que o perfil empreendedor sustentava-se na inovação e na renovação tecnológica, estimulando o progresso econômico. Já McClelland (1972) identificou como principal característica do perfil empreendedor, a necessidade de atingir seus alvos com a dedicação e a disciplina de um estrategista militar, que analisa o terreno onde pisa, procura antecipar riscos e possíveis resultados, de forma obstinada e disciplinada para alcançar seus objetivos.

Posteriormente, Drucker (1987) descreveu empreendedores como indivíduos capazes de aproveitar oportunidades para criar as mudanças. Estes não se limitam apenas aos seus próprios talentos (intuição, criatividade e intelectualidade), levando ao ato de empreender recursos interdisciplinares adquiridos com a experiência e o conhecimento.

No Brasil, este interesse remonta ao início dos anos 90 quando o desenvolvimento de novos negócios começou a se ampliar de forma significativa no país, o que segundo Dornelas (2001) se deu como produto do impacto que os diversos planos econômicos provocaram na economia gerando o fechamento de inúmeras empresas, levando ao aumento do desemprego e alavancando o empreendedorismo por necessidade. As iniciativas empreendedoras passaram a ser uma alternativa à falta de emprego e ao cenário negativo que imperava naquela década. Esta falta de trabalho fez com que muitos utilizassem suas economias e indenizações para abertura de pequenos negócios para os quais não possuíam o perfil nem as competências necessárias, tornando-se este o principal gargalo à sobrevivência e ao sucesso dos negócios nascentes nos últimos 20 anos, como revela a pesquisa de Filardi et al. (2012).

Entretanto, Dolabela (1999) e Filion (1999) afirmam que, no Brasil, por conta da variedade e diversidade de características atribuídas ao empreendedor, o desenvolvimento de estudos que vislumbram a mensuração e o entendimento deste conceito subjetivo, identificando os atributos que contribuem para formação do perfil empreendedor, torna-se cada vez mais relevantes.

Mais recentemente a investigação das características empreendedoras tem conquistado maior destaque, como aponta o trabalho de Silva et al (2013) que em um levantamento bibliométrico identificou que entre 2003 e 2012 foram apresentados 61 trabalhos no Encontro da Associação Nacional de Pós-Graduação e Pesquisa em Administração - EnAnpad sobre as características inerentes aos empreendedores, o tema relacionado ao empreendedorismo com mais publicações.

Neste ponto surgem as questões de pesquisa que dão origem a esta investigação: Quais são as características consideradas fundamentais no perfil empreendedor? Como elas evoluíram ao longo do tempo? Que características se mantiveram? Quais desapareceram? Quais surgiram?

Para responder às questões propostas, este estudo teve o objetivo de investigar a evolução das características do perfil empreendedor no decorrer das últimas três décadas, ou seja, partindo de 1983 até 2014 tomando como ponto de partida os estudos de Kuratko e Hodgetts (1995) "Entrepreneurship: A Contemporary Approach. The Dryden Press Series in Management”, em especial, o quadro de características do perfil empreendedor (Figura 1), onde foram elencadas 25 características desde 1848 até 1982, procurando complementar e ampliar os achados da pesquisa de Filardi et al. (2011), buscando atualizar os resultados já existentes e apresentando novas revelações e tendências.

Este artigo encontra-se organizado em seis seções, partindo desta introdução, passando pela revisão da literatura, seguido do detalhamento do percurso metodológico utilizado e da análise dos resultados, finalizando com as conclusões e referencial utilizado.

\section{REVISÃO DA LITERATURA}

\subsection{A Origem do Empreendedorismo}

Schumpeter (1982) de maneira simplificada resumiu o empreendedorismo no conceito de inovação, no qual ele enaltece a importância empreendedora para a criação de prosperidade. De forma inovadora define o empreendedorismo através do termo destruição criativa, considerando revolucionária a atuação empreendedora sobre a economia do país.

As pesquisas sobre o tema multiplicaram-se ao longo dos anos e as definições mostraram muitas discordâncias. $\mathrm{O}$ perfil abundante do empreendedorismo, não impediu uma centralização das teorias para indicá-lo na direção da criação de empresas ou desenvolvimento daquelas já existentes (Degen, 1989).

O empreendedorismo tem a característica especial de ser produto de vários segmentos do ensino de administração, nos quais, autores importantes o 
definem como o próprio nascimento de um negócio (Filion, 1999; Low, 2001). Outros autores de forma mais flexível entendem o fenômeno como algo ligado à inovação e exigências do mercado (Cordeiro \& Paiva Jr, 2003). Diante do cenário apresentado o empreendedorismo assume maior valor para a estrutura de conhecimento em administração.

O ensino do empreendedorismo teve procedência em Harvard nos Estados Unidos onde, em 1947, foi ministrado o primeiro curso sobre o tema, com o objetivo a época de auxiliar os militares depois da segunda guerra mundial a encontrar novas possibilidades no mercado, com destaque para as oportunidades de novos negócios em vista das dificuldades do pós-guerra. A evolução do ensinamento do empreendedorismo se deu muito lentamente sendo que somente nos anos 70 as universidades americanas começaram a valorizar o tema em seus currículos (Vesper \& Gartner, 1997).

O precursor dos estudos de empreendedorismo foi o Small Business Administration Center (SBAC) localizado em Washington, Distrito de Columbia, que por meio de programas de apoio financeiro às universidades incentivava à implementação de atividades e treinamentos para atuação de alunos como consultores de empresas. (Guimarães, 2002). Em 1994, cerca de 120.000 estudantes já frequentavam cursos de empreendedorismo nos Estados Unidos, e em 2004, aproximadamente 5,6 milhões de jovens com até 34 anos, investiam no seu primeiro empreendimento (Katz, 2003; Kuratko, 2004).

No Brasil, o empreendedorismo surge nas universidades em momento mais recente devido às características da tardia industrialização do país, que apenas nos anos 90 começou a constatar um elevado aumento dos cursos de administração e por conseguinte do ensino e pesquisa sobre empreendedorismo. Segundo o censo da educação superior, executado pelo Instituto Nacional de Estudos e Pesquisas Educacionais Anísio Teixeira - INEP (2010), autarquia subordinada ao Ministério da Educação, aproximadamente 1.004.303 alunos estudavam administração em 2010, ao passo que este número era de 275.966 em 1998.

Segundo Souza e Lopez Jr, (2005), a criação de uma metodologia para o desenvolvimento de competências empreendedoras envolve bem mais que a aquisição de conhecimentos, mas o aprender a aprender, a ser, a fazer e, principalmente a conviver. Isto significa que é necessário, antes de tudo, compreender as reais necessidades para que assim seja possível desenvolver uma metodologia que atenda tais premissas.

Ramos e Ferreira (2004) recorrem à teoria dos sistemas de Bertalanffy (1976) na tentativa de definir empreendedorismo, na qual o empreendedorismo é referenciado como um sistema aberto que possui a finalidade de promover melhor aproveitamento dos recursos sociais, materiais e cognitivos. Há de se ressaltar que todos estes elementos são encontrados em seu ambiente.

Demonstrando entendimento semelhante, Gomes, Forte, Melo e Fontenele (2008) detectam que diante das dificuldades e indecisões, o progresso das organizações está extremamente ligado a indivíduos empreendedores capazes de alcançar novos objetivos de negócio, mostrando antecipação de fatos e alavancando novas habilidades para consecução de suas metas. Esta constatação ratifica a crescente importância do estudo sobre a evolução do empreendedor e suas características.

Para Vale, Corrêa, e Reis (2014) os motivos que levam um indivíduo a empreender ultrapassam a lógica binária de oportunidade versus necessidade, incluindo: atributos pessoais, mercado de trabalho, insatisfação com emprego, família e influência externa.

\subsection{O Perfil Empreendedor}

Segundo Bolton e Thompson (2000), a origem da palavra empreendedorismo vem de 800 anos atrás, derivada do verbo francês "entreprendre", que significa fazer algo, porém, ainda não há consenso sobre a definição do termo empreendedor. Diversos são os estudos que apontam as características e perfis associados ao termo, ao passo que inúmeros estudiosos buscam definir o termo empreendedor e destacam algumas importantes características.

Schumpeter (1950) entende o empreendedor como promotor de adaptações essenciais ao progresso econômico. Enquanto, Kirzner (1986) considera o empreendedor como aquele que consegue identificar e aproveitar oportunidades que são geradas com o uso de novas tecnologias em substituição de outras, o que remete ao processo, denominado por Schumpeter (1982), de destruição criativa, ou seja, o processo capaz de inserir novas tecnologias, destruindo ou até mesmo suprimindo tecnologias existentes, inclusive tecnologias de gestão.

Para McClelland (1972) e Dornelas (2001) as características do empreendedor baseiam-se na motivação que eles têm por suas atividades, visto que demonstram motivação e determinação extremamente elevada, o que os distingue de outros profissionais que muitas vezes fazem apenas o suficiente para cumprir suas tarefas. Dolabela (1999) e Filion (1999) destacaram que é importante entender o empreendedorismo como algo absorvido por pessoas com diferentes graus de necessidades, não existindo uma fórmula que permita inferir o sucesso ou o fracasso profissional. Da mesma forma, não há padrões psicológicos que possam definir o perfil do indivíduo empreendedor, corroborando a idéia de que determinados perfis crescem com a práxis. 
Para Filion (1999) o empreendedor é alguém com capacidade de estabelecer objetivos claros e encontrar oportunidades de negócios. É um visionário e um indivíduo que faz uso de sua criatividade e conhecimento do ambiente no qual está inserido para vislumbrar oportunidades. Dolabela (2002) amplia esta idéia definindo o empreendedor como indivíduo capaz de identificar as oportunidades, independentemente dos recursos que tem à mão, uma vez que sabe como buscar, gerenciar e capacitar recursos.

Filardi et al. (2012) investigou em seu estudo os principais fatores associados à mortalidade precoce das micro e pequenas empresas e concluiu que as características ligadas diretamente à atuação do empreendedor à frente do negócio mostraram-se decisivas na sobrevivência das empresas estudadas.

O Serviço Brasileiro de Apoio às Micro e Pequenas Empresas - SEBRAE (2013), através de seu site, divulga pesquisas com base em análises estatísticas muito significativas, como por exemplo, o trabalho denominado "Fatores Condicionantes e Taxas de Sobrevivência e Mortalidade das Micro e Pequenas Empresas no Brasil - 2010 - 2013”. Este estudo constatou que $24,4 \%$ das empresas fracassam antes de completar 2 anos de vida e destacou como fatores condicionantes ao sucesso empresarial características agrupadas em três categorias comuns: 1) habilidades gerenciais; 2) capacidade empreendedora e 3) logística operacional.

Já os estudos de Rocha e Freitas (2014) revelam que o perfil empreendedor está balizado nas dimensões de Autorrealização, Planejamento, Inovação e Tolerância a riscos. Neste sentido, a identificação das características que compõem o perfil empreendedor favorece a definição de um constructo acerca do termo empreendedor, bem como dos principais aspectos que contribuem para evitar a mortalidade das empresas, aumentando assim a sobrevivência dos empreendimentos e ressaltando a contribuição da presente pesquisa.

\subsection{Características Empreendedoras}

A pesquisa realizada por McClelland (1961) sobre o perfil empreendedor é até hoje considerada uma das mais importantes acerca do tema, pois, o autor valeu-se de um método de testagem chamado "Thematic Aperception Test (T.A.T) e testes de resolução de problemas". Tanto ele, quanto Degen (1989) expressaram uma visão sintética a respeito do assunto, afirmando que o empreendedor tem a necessidade de realizar coisas novas, de inovar constantemente e de colocar em prática suas idéias.

Na década de 70, McClelland (1972) repetiu a pesquisa com empreendedores de 34 países utilizando como metodologia a aplicação de um questionário tipo survey, cujos resultados foram posteriormente ratificados por uma série de pesquisas adicionais. A pesquisa mostrou o empreendedor como uma pessoa diferenciada pela ânsia de se realizar, mas acima de tudo a pesquisa contribuiu no entendimento do tema, elencando outras dez características, identificadas como fundamentais ao crescimento econômico dos indivíduos e capazes de explicar a aparente dificuldade de grande parte dos empreendedores em identificar oportunidades econômicas que se apresentam no ambiente. Estas características são busca de oportunidades e iniciativas, exigência de qualidade e eficiência, persistência, independência e autoconfiança, correr riscos calculados, buscar informações, estabelecimento de metas, planejamento e monitoramento, comprometimento, persuasão e redes de contatos.

É difícil medir as características de um empreendedor, pois os resultados dependem de definições exatas acerca do perfil que constrói este indivíduo, Schumpeter (1982) Filion (1999) e Pylro (2002) confirmam que as divergências de entendimentos dificultam a definição do verdadeiro perfil empreendedor. Por isso, Carland, Carland e Hoy (1998) desenvolveram o Carland Entrepreneurship Index (CEI), um método para medir o perfil empreendedor. A técnica se vale de informações como personalidade e preferências individuais para obter os pontos chave e definir o perfil empreendedor.

No Brasil, Carvalho, Zerbini e Abbad (2005) também criaram uma escala para medição de capacidades de pequenos empresários denominada de "Medida do Perfil do Empreendedor". Ela foi elaborada usando como critério cinco faces que eles consideraram essenciais para este perfil: "ações de gestão de pessoal; relacionamento com clientes e fornecedores; autodesenvolvimento; controle jurídico e financeiro; e marketing e ambiente". Neste mesmo ano, Nascimento, Dantas e Santos (2005), propuseram a "Escala de Prospecção de Potencial Empreendedor", na qual usaram como critério seis dimensões que consideraram essenciais: "capacidades de decisão, de planejamento, de iniciativa, de criatividade, de tenacidade e de autoconfiança". Essa escala foi testada com um grupo de empresários, e destacou que a característica ligada à personalidade é preponderante nesta avaliação.

O tema Perfil Empreendedor possui uma vasta literatura e pesquisadores dispostos a examinar o tema sob várias vertentes, tais como: relatar os comportamentos prévios (Gatewood \& Shaver, 2002) e (Segal \& Borgia, 2005); pesquisar os métodos de ensino empreendedor (Hindle \& Cutting, 2002; Peterman \& Kennedy, 2003; Eckert et al., 2013); examinar a qualidade das escolas (Cunha, 2004; Perera, Nassif, Negro, Bento, Pramio, \& Ono, 2004); estudar a 
liderança e práxis no planejamento de novos empreendimentos (Greatti, 2004); Perfil empreendedor e desempenho organizacional (Schmidt e Bohnenberger, 2009).

Por isso a quantidade de particularidades detectadas por estes vários pesquisadores cresce exponencialmente, dificultando a definição do que seja o "perfil exato do empreendedor." Academicamente, vem-se, ao longo dos anos, tentando desvendar este enigma tão instigante, e com ele responder às perguntas: Quais características compõem o Perfil Empreendedor? Como este perfil evoluiu? Como se adaptou às novas exigências do mundo dos negócios?

Até o momento, a tendência tem sido definir os empreendedores como aqueles que têm sucesso em seus empreendimentos. Como características apontamse a coragem em se arriscar, a visão das chances apresentadas pelo mercado, a interação do indivíduo e o empreendimento, a limitação das possibilidades, a firmeza de ação, a iniciativa, a celeridade e o pensamento positivo (Dornelas, 2001; Salim, Nasajon, Salim \& Mariano, 2004).
Dornelas (2001) defende também que as características empreendedoras baseiam-se na capacidade de intuir, de buscar riqueza, de planejar, de criar valor à sociedade, no networking e na visão de futuro. Para McClelland (1972) e Degen (1989), o empreendedor é aquele que apresenta predisposição para trabalhar continuamente até alcançar os objetivos, quando desafiado por uma oportunidade. É aquele também que identifica a oportunidade, determina os recursos necessários, organiza-os e conduz o desempenho da organização.

Diante desta diversidade de definições, Kuratko e Hodgetts (1995) propuseram-se a sintetizar e classificar as características empreendedoras. Para tal, construíram um quadro referencial (Tabela 1) com as principais características citadas em obras dos mais diversos autores, desde meados do século XIX até o ano de 1982. Neste trabalho, o quadro original foi nomeado como Características do Perfil Empreendedor Tradicional.

Tabela 1 - Quadro de Características do Perfil Empreendedor Tradicional

\begin{tabular}{|c|c|c|}
\hline ANO & AUTOR & CARACTERÍSTICAS \\
\hline 1848 & Mill & Assume risco \\
\hline 1917 & Weber & Fonte da autoridade formal (é líder) \\
\hline 1934 & Shumpeter & Inovação; Iniciativa \\
\hline 1954 & Sutton & Procura desafios \\
\hline 1959 & Hartman & Fonte de autoridade formal (é líder) \\
\hline 1961 & McClelland & Tomador de risco; Necessidade de realização \\
\hline 1963 & Davids & Ambicioso; Procura ser independente; Responsável; Auto-confiante \\
\hline 1964 & Pickle & $\begin{array}{l}\text { Autoconsciência; Relações Humanas; Habilidade em se comunicar; Conhecimento } \\
\text { Técnico }\end{array}$ \\
\hline 1965 & Litzinger & Preferência pelo risco; Independente; Reconhecimento por Benevolente; Líder \\
\hline 1965 & Schrage & $\begin{array}{l}\text { Perceptivo; Motivado pelo poder; Consciente das suas } \\
\text { limitações; Desempenha-se sob pressão }\end{array}$ \\
\hline 1971 & Palmer & Assume risco moderado \\
\hline 1971 & Hornaday e Aboud & $\begin{array}{l}\text { Necessidade de realização; Autonomia; Agressivo; Poder; Reconhecimento; } \\
\text { Inovador/independente }\end{array}$ \\
\hline 1973 & Winter & Precisa de poder \\
\hline 1974 & Borland & Foco interno de controle \\
\hline 1974 & Liles & Necessidade de realização \\
\hline 1977 & Gasse & Orientado por valores pessoais \\
\hline 1978 & Timmons & $\begin{array}{l}\text { Autoconfiante; orientado para resultado; tomador de risco moderado; foco no } \\
\text { controle; criativo/inovador }\end{array}$ \\
\hline 1980 & Brockhaus & Tendência a assumir risco \\
\hline 1980 & Sexton & Enérgico/ambicioso; pró-ativo \\
\hline 1981 & Mescon e Montanari & Realização; Domínio; Autonomia; Paciente; Posição de controle \\
\hline 1981 & Welsh and White & $\begin{array}{l}\text { Necessidade de controlar; Responsável; Auto-confiante; Aceita desafios; Tomador } \\
\text { de risco moderado }\end{array}$ \\
\hline 1982 & Dunkelberg e Cooper & Orientado para o crescimento e para independência \\
\hline 1982 & Welsch e Young & Posição de controle; Aberto a inovações; Auto-estima \\
\hline
\end{tabular}

Fonte: Kuratko \& Hodgetts (1995). 
Este é o ponto de partida do presente estudo, cujo método de pesquisa utilizado para complementar o trabalho desenvolvido por Kuratko e Hodgetts (1995), será descrito detalhadamente na próxima sessão.

\section{METODOLOGIA}

A maior motivação para este estudo foi dar continuidade ao trabalho desenvolvido por Filardi et al. (2011), buscando complementar a pesquisa de Kuratko e Hodgetts (1995) e acompanhar a evolução das características empreendedoras através de uma pesquisa de caráter descritivo, explicativo e bibliométrico, envolvendo técnicas padronizadas de coleta de dados e observação sistemática da produção acadêmica ligada ao perfil empreendedor na literatura nacional e internacional.

De acordo com Vergara (2009), uma pesquisa descritiva expõe características sobre determinada população ou fenômeno, estabelecendo correlações entre as variáveis adquiridas através do uso de técnicas padronizadas para coleta de dados. A forma de levantamento de dados contribui com a estrutura e o desenvolvimento do tema. Enquanto a pesquisa bibliométrica sistematiza o estudo com base em material publicado, o enfoque explicativo viabiliza a compreensão do tema, justificando-lhe as razões.

Segundo Gil (1999), este estudo pode ser considerado quantitativo, uma vez que por meio de análise de dados traduziu-se em números opiniões e informações, classificando-as e analisando-as através do uso de recursos e de técnicas estatísticas. Os dados coletados visam permitir a descrição do perfil empreendedor, possibilitando a ampliação do conhecimento sobre o tema, bem como sobre as obras e seus autores.

$\mathrm{Na}$ análise da produção científica sobre o tema foram utilizados indicadores bibliométricos, buscando investigar a evolução das características empreendedoras citadas pelos autores em diversas fontes importantes explicitadas mais adiante. A seguir, será apresentado o percurso metodológico da coleta de dados.

\subsection{Coleta dos dados}

A coleta de dados que deu origem a este trabalho teve um recorte temporal de 31 anos, tendo como objetivo complementar a pesquisa de Kuratko e Hodgetts (1995), que abrange o período de 1848 e 1982. Por isso, nesta etapa buscou-se trabalhos publicados entre 1983 e 2014, consolidando o estudo de Filardi et al (2011) e ampliando as bases de dados utilizadas para análise das Características do Perfil Empreendedor Contemporâneo.

Para este levantamento bibliográfico foram selecionados artigos publicados nos periódicos científicos nacionais mais bem classificados de acordo com o sistema Qualis de classificação de periódicos e eventos, composto pela Revista de Administração de Empresas - RAE, pela Revista de Administração Contemporânea - RAC e pelos eventos científicos ENANPAD e EGEPE, onde por meio da identificação e extração das informações pertinentes ao tema foram obtidos subsídios necessários à produção desta pesquisa.

O levantamento foi realizado utilizando as palavras-chave Empreendedor, Empreendedorismo, Características Empreendedoras, Atitudes Empreendedoras e Perfil Empreendedor. É relevante destacar que na base de dados do EGEPE foram selecionados apenas os artigos apresentados até a edição de 2012, já que os da edição de 2014 não estavam no sistema de buscas.

A base de dados EBSCO foi utilizada para selecionar artigos publicados nos periódicos científicos internacionais mais bem classificados no sistema Qualis e dentre as publicações, foram selecionadas apenas as classificadas como A1 e A2 na área de administração, ciências contábeis e turismo, a saber: Applied Financial Economics; Applied Economics Letters; Management Research Review; Journal of Product Innovation Management; European Management Journal; Service Industries Journal; International Journal of Entrepreneurship \& Innovation Management; Entrepreneurship: Theory \& Practice; Journal of International Entrepreneurship; Management Decision; International Small Business Journal.

O levantamento foi realizado utilizando as palavras-chave entrepreneur ${ }^{*}$ attitude $O R$ entrepreneur* profile ${ }^{*}$ ontrepreneur* characteristcs, o idioma dos trabalhos foi filtrado para Inglês e a pesquisa foi refinada para selecionar apenas artigos de revistas acadêmicas, possibilitando, com isso, a manutenção das mesmas referências para artigos nacionais e internacionais.

\subsection{Tratamento dos dados}

Foram selecionados para compor este trabalho, os artigos que em seu conteúdo apresentaram estudos sobre as características formadoras do perfil empreendedor. Inicialmente, como técnica de seleção do material a ser avaliado, examinou-se os títulos, resumos e palavras-chave de cada artigo obtido nas buscas efetuadas. 
Na continuidade do processo de pré-seleção, foi feito download de todos os artigos que atenderam aos critérios estabelecidos na pesquisa, sendo os mesmos organizados por ano de publicação. Somente após esta avaliação preliminar, iniciou-se a análise aprofundada do conteúdo apresentado nos textos da introdução, da análise de resultados e da conclusão destes artigos, dos quais foram extraídas e tabuladas as características empreendedoras identificadas.

Tal ordenação foi feita em uma planilha de dados eletrônica, cuja organização deu-se através dos campos ano de publicação, título, autor e característica, perfil ou atitude empreendedora explicitada no artigo. A opção por tal método de tabulação visou facilitar a visualização das informações necessárias ao estudo, bem como os relacionamentos entre as diversas obras e seus autores.

Após a busca, leitura dos títulos, resumos e palavras-chave dos trabalhos, foram selecionados 288 artigos de origem nacional e internacional, os quais foram analisados com maior profundidade por terem sido considerados relevantes para o cumprimento do objetivo deste estudo. Após essa análise, foram definidos de fato 156 artigos e 341 autores a serem considerados para compor esta pesquisa, tendo como critério de mensuração a não repetição de seus nomes durante processo de análise e tabulação. Desta forma, evitou-se concentrar o estudo em um grupo restrito de pesquisadores, buscando enriquecer a pesquisa com as mais diversas visões.

No que tange a tabulação das características, durante a avaliação dos artigos algumas regras foram observadas: 1 - não foram somadas as características que se repetiam no mesmo ano; 2 - foram aproveitadas apenas uma vez as características repetidas, provenientes de artigos diferentes do mesmo autor; e 3 - foram aproveitadas as características provenientes de artigos de mesmo autor, desde que feitos em conjunto com outros autores.

Para o aprimoramento do estudo, foi necessário consolidar o entendimento de algumas características, pois, enquanto na tabela contemporânea uma característica foi explicitada como 'Tolerante a Risco', por exemplo, na tabela tradicional é descrita de várias formas (assume risco, tomador de risco, etc.). Assim, após leitura do texto e verificação do sentido proposto pelos autores, foi criado um Quadro de Similaridades de Significados (Tabela 2), a fim de facilitar a análise comparativa.

Tabela 2 - Quadro de Similaridades de Significados

\begin{tabular}{|l|l|}
\hline \multicolumn{1}{|c|}{ TRADICIONAL } & \multicolumn{1}{|c|}{ CONTEMPORÂNEO } \\
\hline $\begin{array}{l}\text { Assume risco, Tomador de risco, Preferência pelo risco, Assume risco } \\
\text { moderado, Tomador de risco moderado, Tendência a assumir risco }\end{array}$ & Tolerante a risco \\
\hline Fonte da Autoridade Formal (é líder), Líder & Líder \\
\hline Inovação, Inovador, Aberto a inovações & Inovador \\
\hline Iniciativa, Pró-ativo & Pró-ativo \\
\hline Procura desafios, Aceita desafios & Corajoso \\
\hline Ambicioso, Motivado pelo poder, Poder, Precisa de Poder & Ambicioso \\
\hline Procura ser independente, Independente, Orientado para independência & Independente \\
\hline Relações Humanas & Interpessoal \\
\hline Habilidade de se comunicar & Comunicativo \\
\hline Conhecimento técnico & Qualificado \\
\hline $\begin{array}{l}\text { Foco interno de controle, Foco no controle, Posição de controle, Necessidade } \\
\text { de controlar, Domínio }\end{array}$ & Controlador \\
\hline Necessidade de Realização, Reconhecimento, Realização & Necessidade de Realização \\
\hline Orientado para resultado, Orientado para crescimento & Objetivo \\
\hline
\end{tabular}

Fonte: Autores 2014.

Ao final da tabulação foram identificadas 122 características empreendedoras, e para cada uma foi contabilizada a quantidade de anos em que foi citada. Finalizados os somatórios, foram consideradas relevantes para compor este trabalho apenas as 27 características mais citadas. O critério para definir esta relevância baseou-se em regra comparativa, na qual, primeiro verificou-se qual a característica mais citada, que foi pró-ativo, presente em 23 anos do período estudado, e posteriormente, definiu-se que seriam aproveitadas as características presentes em pelo menos 5 anos. A seguir, será apresentada a análise dos resultados de forma agregada contemplando o período de 1983 a 2014. 


\section{APRESENTAÇÃO E ANÁLISE DOS RESULTADOS}

A luz do trabalho de Kuratko e Hodgetts (1995), cuja tabela 1 apresenta as características do perfil empreendedor denominado neste trabalho como TRADICIONAL (apresentado no referencial teórico), construiu-se um quadro similar denominado como CONTEMPORÂNEO (tabela 3), com base nas características levantadas por esta pesquisa. Nesta análise, a proposta foi comparar as características, apontando semelhanças, diferenças, evoluções e possíveis explicações que justifiquem as alterações observadas.

As características selecionadas para compor a tabela contemporânea mostram que, apesar das instabilidades ocorridas no período analisado, houve grande aumento na produção científica nacional e internacional direcionada ao empreendedorismo, ao perfil empreendedor e suas características. Vale registrar a contribuição relevante dos Encontros Nacionais da ANPAD (EnANPAD), criado em 1997, e que desde 2003 reserva uma área temática para a apresentação de trabalhos sobre empreendedorismo e comportamento empreendedor, fomentando as discussões e enriquecendo a base de conhecimento à respeito do tema, o que pode justificar a grande quantidade de artigos sobre o tema encontrados no estudo de Silva et al (2013). Igualmente, é relevante destacar a quantidade considerável de artigos do EGEPE de 2012 selecionados para este estudo, o que justifica o número elevado de autores neste ano.

Tabela 3 - Quadro de Características do Perfil Empreendedor Contemporâneo.

\begin{tabular}{|c|c|c|}
\hline ANO & AUTOR & CARACTERÍSTICAS \\
\hline 1983 & Long & Inovador e Tolerante à Risco \\
\hline 1984 & $\begin{array}{l}\text { J. W. Carland, J. A. Carland, Hoy e } \\
\text { Boulton }\end{array}$ & Inovador \\
\hline 1985 & Marshall e Gartner & Pró-ativo \\
\hline 1986 & Aldrich, Auster, Bowen e Hisrich & Interpessoal e Autoconfiante \\
\hline 1987 & Neider e Drucker & Pró-ativo, Determinado, Ambicioso, Perseverante e Inovador \\
\hline 1988 & Dimaggio & Inovador e Pró-ativo \\
\hline 1989 & Degen & Inovador e Pró-ativo \\
\hline 1990 & Bowman-Upton & Inovador e Independente \\
\hline 1991 & Filion & Criativo, Visionário e Pró-ativo \\
\hline 1992 & Macmillian & Tolerante à Risco \\
\hline 1993 & Amit & Inovador e Tolerante à Risco \\
\hline 1994 & Timmons & Pró-ativo, Visionário, Tolerante à Risco e Flexível \\
\hline 1995 & Pati & $\begin{array}{l}\text { Pró-ativo, Visionário, Estrategista, Interpessoal, Corajoso, Motivado, } \\
\text { Intuitivo, Independente, Organizado, Líder e Criativo }\end{array}$ \\
\hline 1996 & Lumpkin, Dess, Brush e Bird & Pró-ativo, Inovador, Flexível, Tolerante à Risco, Criativo, Visionário \\
\hline 1997 & C. Cunha e Ferla & Pró-ativo \\
\hline 1998 & $\begin{array}{l}\text { Drucker, Amabile, Echeveste, Vieira, } \\
\text { Viana, Trez e Panosso }\end{array}$ & $\begin{array}{l}\text { Inovador, Motivado, Líder, Interpessoal, Flexível, Qualificado, } \\
\text { Experiente e Criativo }\end{array}$ \\
\hline 1999 & Dolabela, Daft e Machado & Pró-ativo, Corajoso, Intuitivo e Determinado \\
\hline 2000 & $\begin{array}{l}\text { Morais, Bruyat, Julien, Sexton e } \\
\text { Landstöm }\end{array}$ & Tolerante à Risco, Pró-ativo, Inovador e Ambicioso \\
\hline 2001 & $\begin{array}{l}\text { Kets de Vries, Dornelas, Pelisson, L. A. } \\
\text { Aligleri, Gimenez, V. Gomes e L. M. } \\
\text { Aligleri }\end{array}$ & $\begin{array}{l}\text { Tolerante à Risco, Perseverante, Motivado, Líder, Comprometido } \\
\text { (Criar Valor à Sociedade), Otimista, Independente, Habilidoso, } \\
\text { Planejador, Flexível e Criativo }\end{array}$ \\
\hline 2002 & Guimarães, Cardoza, Inácio Jr. & $\begin{array}{l}\text { Inovador, Determinado, Perseverante, Criativo, Tolerante à Risco, } \\
\text { Flexível, Ambicioso, Autoconfiante e Pró-ativo }\end{array}$ \\
\hline 2003 & $\begin{array}{l}\text { Diaz, Rodriguez, } \\
\text { Bernardes, Marcondes, Zilber, Almeida, } \\
\text { Castilho, Vidal, Filho, Ferreira, Mattos, } \\
\text { Ayres, Meurer, Previdelli e Dutra }\end{array}$ & $\begin{array}{l}\text { Tolerante à Risco, Criativo, Organizado, Habilidoso, Experiente, } \\
\text { Qualificado, Visionário, Motivado, Interpessoal, Líder, Perseverante, } \\
\text { Comprometido (Criar Valor à Sociedade), Comunicativo, Autônomo, } \\
\text { Determinado, Intuitivo, Objetivo e Ambicioso }\end{array}$ \\
\hline 2004 & $\begin{array}{l}\text { Gerber, Sohn, Kiesel, R. Cunha, Nassif, } \\
\text { Ghobril, Costa, Lenzi, N. Silva, } \\
\text { Guardani, Leão, Cordeiro, Mello, Espejo } \\
\text { e Greatti }\end{array}$ & $\begin{array}{l}\text { Estrategista, Inovador; Criativo; Pró-ativo, Qualificado, Otimista, } \\
\text { Líder, Flexível, Independente, Tolerante à Risco, Habilidoso, } \\
\text { Perseverante, Corajoso, Autônomo, Comunicativo, Ambicioso, } \\
\text { Comprometido (Criar Valor à Sociedade), Experiente e Intuitivo }\end{array}$ \\
\hline 2005 & $\begin{array}{l}\text { Lambooy, Reyes, Vale, Benedetti, } \\
\text { Rebello, Borba, Amâncio, E. Souza, } \\
\text { Daros, Dantas, Lopez Jr., P. Santos, }\end{array}$ & $\begin{array}{l}\text { Tolerante à Risco, Inovador, Visionário, Otimista, Ambicioso, } \\
\text { Estrategista, Planejador, Objetivo, Pró-ativo, Perseverante, } \\
\text { Comprometido (Criar Valor à Sociedade), Organizado, Interpessoal, }\end{array}$ \\
\hline
\end{tabular}




\begin{tabular}{|c|c|c|}
\hline & $\begin{array}{l}\text { Wilkinson, Mallmann, Ruppenthal, } \\
\text { Nascimento Jr., Carvalho, Bizzarri e } \\
\text { Venturi }\end{array}$ & $\begin{array}{l}\text { Líder, Independente, Autoconfiante, Criativo, Habilidoso, Flexível, } \\
\text { Determinado e Autônomo }\end{array}$ \\
\hline 2006 & $\begin{array}{l}\text { Paiva Jr., Leite, C. Souza, Christopoulos, } \\
\text { Fontanelle, Hoeltgebaum, Silveira, } \\
\text { Corrêa, M. Oliveira, Lima, Grisci, } \\
\text { Gouveia, J. Dias, Castanhar, Esperança, } \\
\text { Gonçalves, D. Oliveira, S. Santos, } \\
\text { Gosling, Callado, J. Gomes e Tavares }\end{array}$ & $\begin{array}{l}\text { Tolerante à Risco, Inovador, Visionário, Pró-ativo, Interpessoal, } \\
\text { Ambicioso, Planejador, Organizado, Criativo, Perseverante, Líder, } \\
\text { Comprometido (Criar Valor à Sociedade), Independente, } \\
\text { Autoconfiante, Determinado, Flexível, Autônomo, Objetivo, } \\
\text { Qualificado e Otimista }\end{array}$ \\
\hline 2007 & $\begin{array}{l}\text { Bingham, Eisenhardt, Furr, Miller, } \\
\text { Baron, Hitt, Snow, Wadeson, Castro- } \\
\text { Lucas, Cassol, Viet, Gonçalvez Filho, } \\
\text { Bohnenberger, Freitas, Schmidt, V. Dias, } \\
\text { Secco, Pessoa, Wetzel, Paixão, Bruni, } \\
\text { Carvalho Jr., Amaral, Pinto, M. Soares, } \\
\text { Godoi, Cosenza, Feuerschütte, J. } \\
\text { Oliveira, Veiga e Villela }\end{array}$ & $\begin{array}{l}\text { Tolerante à Risco, Inovador, Visionário, Pró-ativo, Flexível, Otimista, } \\
\text { Determinado, Líder, Ambicioso, Criativo, Perseverante, Corajoso, } \\
\text { Interpessoal, Planejador, Comunicativo, Autônomo, Motivado, } \\
\text { Independente, Experiente, Habilidoso, Estrategista, Objetivo, } \\
\text { Intuitivo, Autoconfiante, Comprometido (Criar Valor à Sociedade) e } \\
\text { Organizado. }\end{array}$ \\
\hline 2008 & $\begin{array}{l}\text { Cavusgil, Ciuchta, Villanueva, De Toni, } \\
\text { Milan, Schuler, Dorion, Gouvea, E. } \\
\text { Gomes, Forte, Melo, Fontenele e } \\
\text { Pedrosa }\end{array}$ & $\begin{array}{l}\text { Tolerante à Risco, Inovador, Pró-ativo, Ambicioso, Experiente, } \\
\text { Autoconfiante, Organizado, Planejador, Líder, Interpessoal, } \\
\text { Comunicativo, Visionário, Intuitivo, Estrategista, Perseverante, } \\
\text { Objetivo, Criativo, Corajoso, Independente, Autônomo e Otimista }\end{array}$ \\
\hline 2009 & $\begin{array}{l}\text { A. Gomes, Borges, Casado, Santanta, } \\
\text { Araújo, A. Santos e Alves }\end{array}$ & $\begin{array}{l}\text { Tolerante à Risco, Flexível, Otimista, Determinado, Visionário, Líder, } \\
\text { Ambicioso, Planejador, Inovador, Criativo, Pró-ativo, Comunicativo, } \\
\text { Interpessoal, Autoconfiante, Organizado, Corajoso, Intuitivo, } \\
\text { Estrategista, Experiente, Comprometido (Criar Valor à Sociedade), } \\
\text { Perseverante e Autônomo }\end{array}$ \\
\hline 2010 & $\begin{array}{l}\text { Henry, Valadares, Emmendoerfer, G. } \\
\text { Silva, E. Soares, Leal, Guedes e } \\
\text { Fabricio. }\end{array}$ & $\begin{array}{l}\text { Tolerante à Risco, Pró-ativo, Otimista, Inovador, Criativo, Líder, } \\
\text { Visionário, Qualificado, Experiente e Interpessoal }\end{array}$ \\
\hline 2011 & $\begin{array}{l}\text { Vale, Serafim, Teodósio, Elias, Oliveira } \\
\text { Filho, Oliveira, Pelogio, Rocha, } \\
\text { Machado, Añez, Minello, Gomes, } \\
\text { Scherer, Lopes, Scherer, Alves, Perlin, } \\
\text { Huezo, Fontenele, Pereira, Sousa, } \\
\text { Mariano, Moraes, Medeiros, D. Urbano, } \\
\text { Toledano, Ribeiro-Soriano e Xu }\end{array}$ & $\begin{array}{l}\text { Inovador, Tolerante à Risco, Pró-ativo, Interpessoal, Autoconfiante, } \\
\text { Determinado, Perseverante, Ambicioso, Independente, Criativo, } \\
\text { Visionário, Flexível, Estrategista, Motivado, Líder, Qualificado, } \\
\text { Experiente, Comprometido (Criar Valor à Sociedade), Planejador, } \\
\text { Organizado, Objetivo, Autônomo. }\end{array}$ \\
\hline 2012 & $\begin{array}{l}\text { Serafim, Martes, Rodriguez, S. } \\
\text { Rodrigues, Child, Ribeiro, Oliveira Jr., } \\
\text { Borini, Zampier, Takahash, A. } \\
\text { Vasconcelos, Lezana, Ésther, I. } \\
\text { Rodrigues, Freire, Minello, Alves, } \\
\text { Scherer; Gomes, Lopes, La Falce, } \\
\text { Muylder, Sarruf, Freitas, V. Andrade, J. } \\
\text { Queiroz, F. C. Queiroz, Jacober, } \\
\text { Hashimoto, Albertini, R. Oliveira, } \\
\text { Sbaraini, Rezende, Furquim, M. } \\
\text { Oliveira, M. Araujo, Prado, E. Machado, } \\
\text { Braga, Lapolli, Bolsson, Boeira, } \\
\text { Medeiros, F. Machado, Silva, Noro, } \\
\text { Munhoz, Nassif, Oliveira Filho, Bueno, } \\
\text { L. Oliveira, Peghini, Portes, Andrade, } \\
\text { Pereira, Guimarães, Ferreira, } \\
\text { Hoeltgebaum, Lorenzi, Klemz, J. } \\
\text { Oliveira, Pires, Patias, V. Vasconcelos, } \\
\text { Matos, Gomes Neto, Melo, Paiva Junior, } \\
\text { Fernandes, Premoli, Souza, Noronha, D. } \\
\text { Andrade, Ribeiro, Babosa, Castro, } \\
\text { Matias, Martins, Amaro, Brunstein, } \\
\text { Moraes, Lizote, Lana, Camargo, Branco, } \\
\text { Lenzi, J. R. Oliveira, Castro Silva, E. } \\
\text { Araujo, Arribas, Hernández, A. Urbano, } \\
\text { Vila, Lin, Tao, Akehursta, Simarrob, } \\
\text { Mas-Tur, Zhao, Erekson, Wang, Michael }\end{array}$ & $\begin{array}{l}\text { Inovador, Tolerante à Risco, Pró-ativo, Interpessoal, Autoconfiante, } \\
\text { Determinado, Perseverante, Ambicioso, Independente, Criativo, } \\
\text { Visionário, Flexível, Estrategista, Corajoso, Líder, Qualificado, } \\
\text { Experiente, Comprometido (Criar Valor à Sociedade), Otimista, } \\
\text { Planejador, Organizado, Comunicativo, Autônomo. }\end{array}$ \\
\hline
\end{tabular}


Do Homo Empreendedor ao Empreendedor Contemporâneo: Evolução das Características Empreendedoras de 1848 a 2014

\begin{tabular}{|c|l|l|}
\hline & $\begin{array}{l}\text { Song, Morris, Kuratko, Schindehutte e } \\
\text { Spivack }\end{array}$ & \\
\hline \multirow{3}{*}{2013} & $\begin{array}{l}\text { Ferreira, Nogueira, Amaro, Brunstein, } \\
\text { Lizote, Veiga, Terres, Godói-de-Sousa, } \\
\text { Buen, Sousa, dos Santos, Estay, Durrieu, } \\
\text { Santandreu-Mascarell, Garzon, Knorr, }\end{array}$ & $\begin{array}{l}\text { Inovador, Tolerante à Risco, Pró-ativo, Interpessoal, Autoconfiante, } \\
\text { Determinado, Perseverante, Ambicioso, Independente, Criativo, } \\
\text { Visionário, Corajoso, Líder, Qualificado, Experiente, Comprometido } \\
\text { (Criar Valor à Sociedade), Planejador, Comunicativo, Objetivo, } \\
\text { Autônomo. }\end{array}$ \\
\hline \multirow{2}{*}{$\mathbf{2 0 1 4}$} & $\begin{array}{l}\text { Vale, Lima Filho, Bruni, Leite, Salazar, } \\
\text { Bracht, Werlang, Obeng, Robson, }\end{array}$ & $\begin{array}{l}\text { Inovador, Tolerante à Risco, Pró-ativo, Interpessoal, Autoconfiante, } \\
\text { Determinado, Perseverante, Ambicioso, Independente, Criativo, } \\
\text { Haugh, Semrau, Werner, Kim e } \\
\text { Vonortas }\end{array}$ \\
\hline
\end{tabular}

Fonte: Autores, 2014, (Resultado da Pesquisa Bibliométrica)

A delimitação do estudo vai de 1983 a 2014, complementando o trabalho Kuratko e Hodgetts (1995) que contemplou o período de 1848 a 1982, e neste período foi possível observar o expressivo aumento da produção referente às características do perfil empreendedor contemporâneo, especialmente na última década, de 2003 a 2013, embora seja apresentada uma queda aparentemente pontual em 2010 e em 2014, que conta com a particularidade de ter sido contemplado apenas até o mês de setembro.

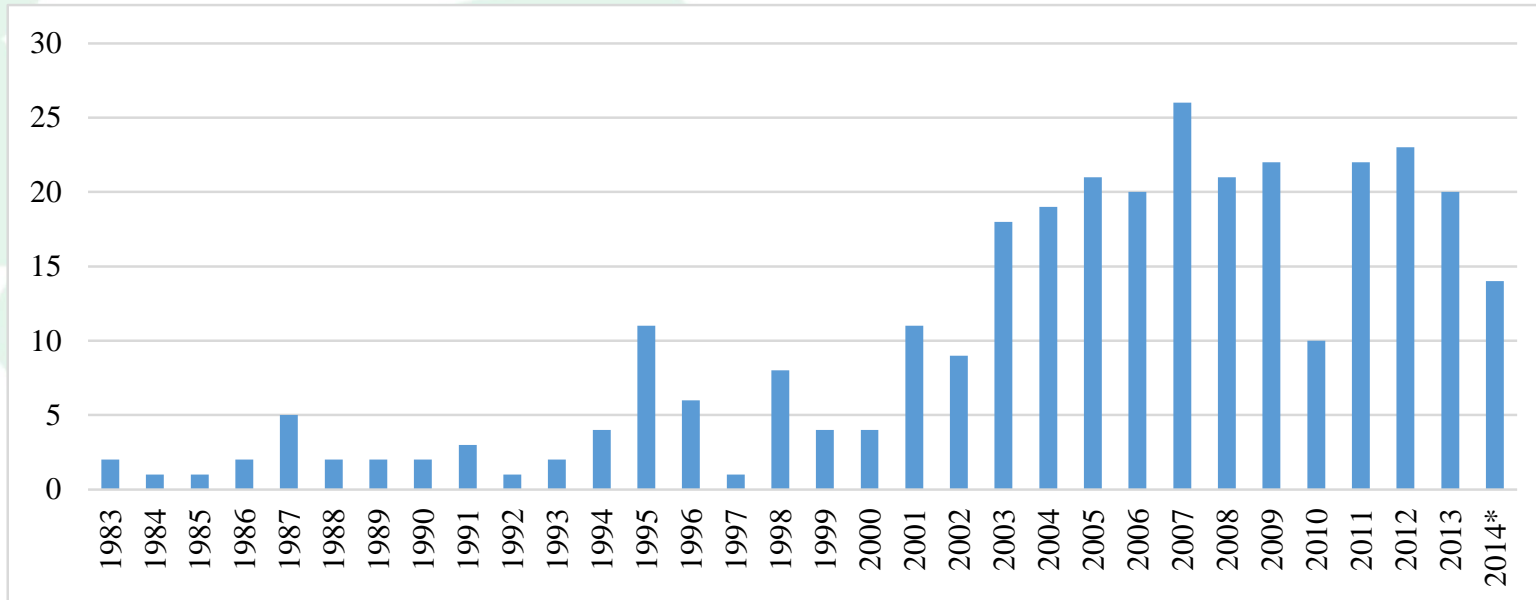

*de janeiro a setembro de 2014

Figura 1 - Quantidade de Características Citadas por Ano. Fonte: Autores, 2014.

Os detalhes dessa evolução cronológica estão demonstrados na figura 1 , onde se pode observar claramente que 2007 foi o ano com maior número de citações de características empreendedoras diferentes, totalizando 26, e demonstrando o aumento da complexidade da definição de perfil empreendedor e características que o compõe.

Outra análise que pode ser feita é a da mudança no perfil dos artigos em co-autoria que tinham de 1 a 2 autores até o ano de 2002 e passam a ter em média 3 autores ou mais, resultado que pode ser explicado pelo maior interesse de pesquisa pelo tema a partir do ano de 2003.

A análise dos dados demonstrados na figura 2, indica que no período contemporâneo algumas características passaram a ser bastante citadas com relação ao perfil empreendedor, como a pró-atividade, que aparece em 23 anos da amostra, a capacidade de inovar, presente em 22 anos, a tolerância a riscos, 20 anos, e a criatividade, 18 anos, evidencia uma necessidade de diferenciação por parte do empreendedor frente ao aumento da concorrência gerado pelo processo de globalização e abertura da economia em diversos países emergentes, especialmente os BRICs, do qual o Brasil faz parte. Segundo Parker (1996), a globalização é o fenômeno capaz de gerar oportunidades de crescimento por meio da criação de infraestrutura empreendedora nos países em desenvolvimento. 
Neste processo de integração mundial, com dissolução das fronteiras geográficas e lingüísticas, surge a possibilidade de virtualizar o mundo dos negócios, exigindo um profissional mais perseverante, visionário e flexível, já que as regras, antes bastante previsíveis, se tornam mutáveis e por vezes imprevisíveis. Além disto, nos últimos 10 anos, a sociedade tornou-se ainda mais participativa e exigente, e os negócios precisaram adaptar-se, exigindo do empreendedor maior comprometimento com a agregação de valor no âmbito social e ambiental.

Esta transformação social pode ser observada também na evolução dos termos utilizados nas definições das características, como por exemplo, o empreendedor deixa de ser agressivo, tornando-se motivado, também não é mais orientado a resultados, mas objetivo, e ao invés de dominar, ele agora controla, evidenciando pequenas alterações que denotam a preocupação com a forma como são vistos pelos clientes e demais stakeholders.

Ainda analisando as revelações da figura 2, é possível verificar que as características do empreendedor interpessoal, perseverante, ambicioso, visionário e líder, aparecem ambas em 14 anos da amostra, apontando para um perfil menos técnico e mais voltado para o lado comportamental e para o relacionamento, que passa a ser extremamente importante na dinâmica dos negócios atuais.

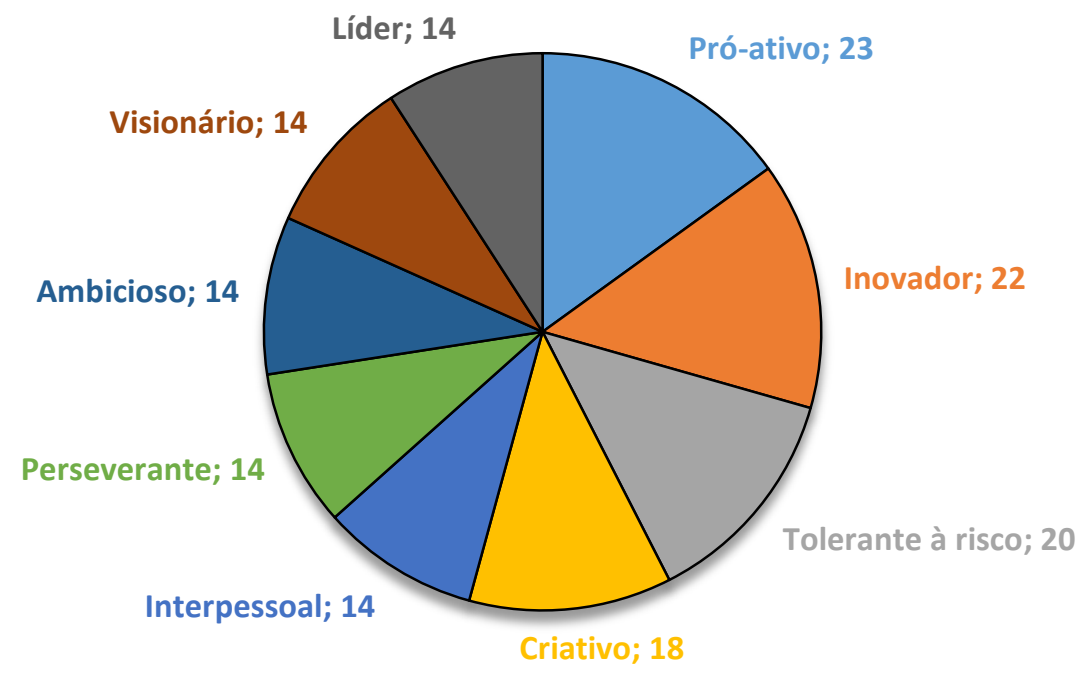

Figura 2 - Características Mais Citadas do Perfil Empreendedor Contemporâneo. Fonte: Autores, 2014.

Na sequência, a figura 3 demonstra a evolução das 10 características mais citadas na tabela tradicional (tabela 1), ou seja até 1982, e como elas estão hoje em termos de citações, revelando-se que diante das adequações necessárias à sobrevivência do profissional em um mercado mais consciente, dinâmico e exigente, aparecem características que resistem à passagem do tempo, outras que surgiram e se consolidaram, ao passo que algumas vem desaparecendo como demonstração da evolução da natureza da atividade de empreender. 
Do Homo Empreendedor ao Empreendedor Contemporâneo: Evolução das Características Empreendedoras de 1848 a 2014

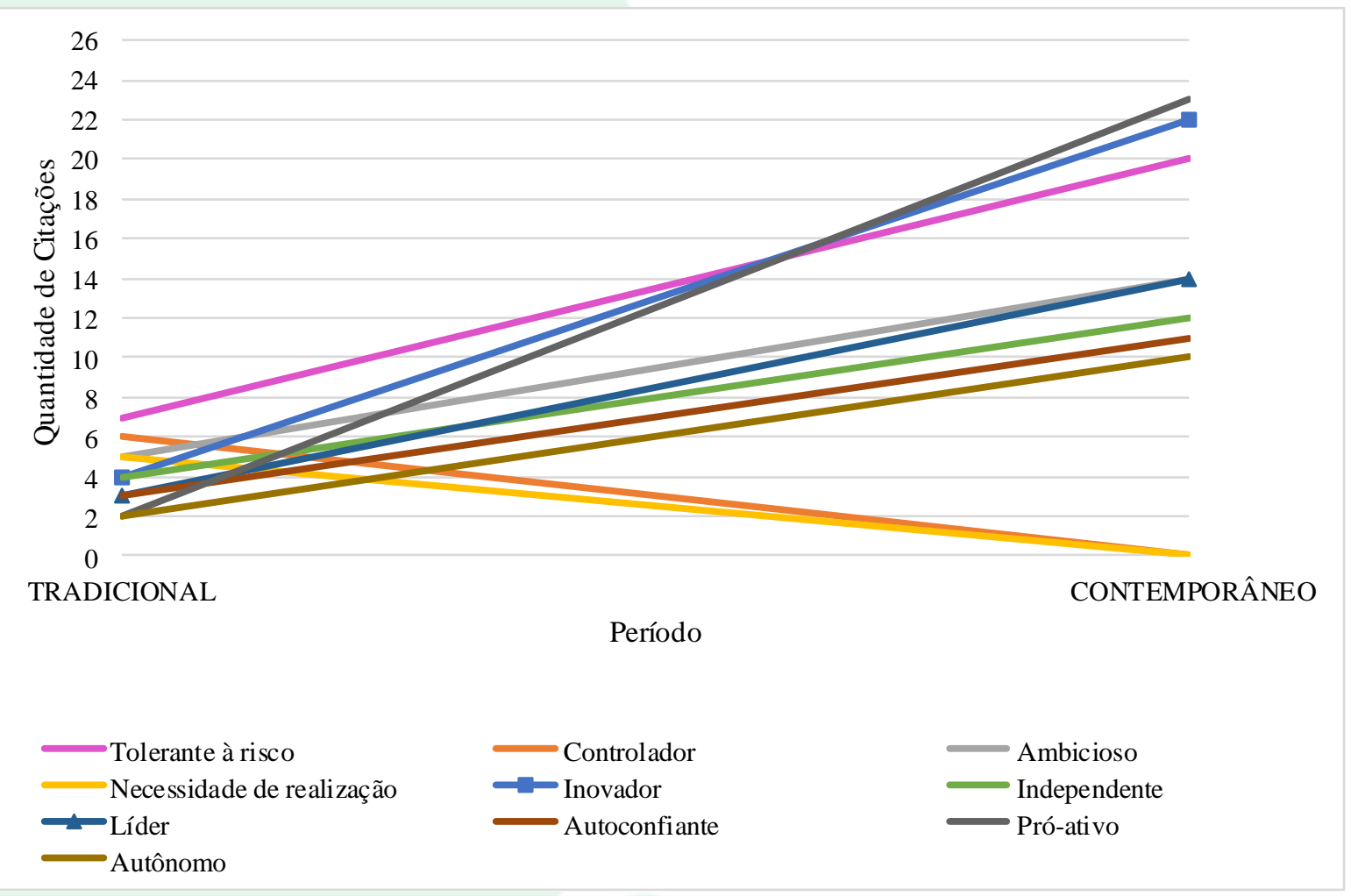

Figura 3 - Evolução das 10 Características mais citadas do Empreendedor Tradicional Fonte: Autores, 2014.

Nos achados da pesquisa que estão ilustrados na figura 3, das dez características mais citadas no perfil tradicional, três tiveram forte ascensão quando se compara com o perfil contemporâneo, sendo que próatividade foi a que registrou maior crescimento saindo de 2 citações nos primórdios do empreendedorismo para 23 citações no período atual. Já a característica de inovação subiu de 4 citações para 22 , seguida de tolerância ao risco, que foi de 7 para 20, o que faz todo o sentido pelo crescente aumento da incerteza pelo qual vem passando a economia. Torna-se importante salientar que todas estas são características de relacionamento externo do empreendedor e reforçam a necessidade de desenvolver uma boa relação com o ambiente externo que o cerca.

Um grupo de características que tiveram ascensão moderada é formado por liderança que passou de 3 para 14 citações, ambição que passou de 5 para 14, independência que passou de 4 para 12, autonomia que foi de 2 para 10, e autoconfiança que saiu de 3 e chegou a 11. A relação entre estas características se dá quando verifica-se que o ponto em comum é o foco em si mesmo, ou seja, características ligadas ao próprio empreendedor e a sua personalidade, que não cresceram com tanto vigor quanto aquelas ligadas ao relacionamento externo.
Já as características de necessidade de controle e de realização tiveram sua importância reduzida ao longo do tempo, não sendo identificadas entre as características do empreendedor contemporâneo, demonstrando uma tendência a necessidade de delegar que o empreendedor deve desenvolver por um lado, e ao foco na realização coletiva ao invés da realização individual.

Já a figura 4 demonstra a evolução das 9 características mais citadas na tabela contemporânea (tabela 3), ou seja, de 1983 a 2014, e como elas estão hoje em termos de citações, revelando que no mundo atual, novas habilidades passaram a ser exigidas do empreendedor, como a visão de futuro, que não aprecia citada na tabela tradicional e é citada 12 vezes na pesquisa atual, a criatividade que evolui de 2 citações para 18 e a perseverança que aumenta de 3 para 12 citações, apontando para uma tendência ao mesmo tempo de antecipar e de insistir para ter sucesso na atividade empreendedora. 


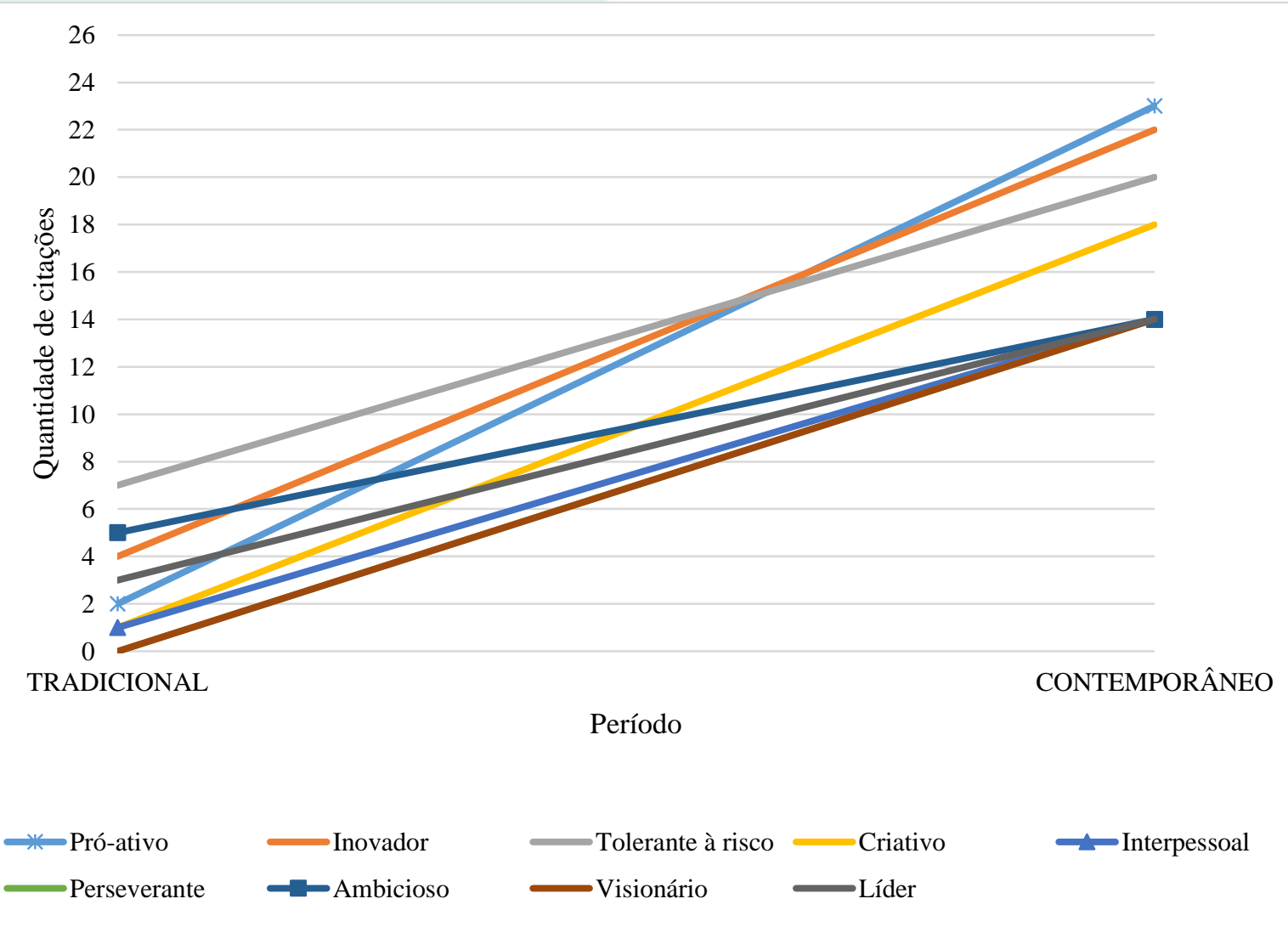

Figura 4. Evolução das 9 Principais Características do Empreendedor Contemporâneo.

Fonte: Autores, 2014.

O período contemporâneo trouxe maior complexidade à atividade empreendedora e ao mercado, transformando a política, a economia, a tecnologia, a natureza e a cultura. A ruptura com o mundo tradicional vem exigindo do empreendedor contemporâneo uma série de competências não citadas anteriormente, como a capacidade de organização, a intuição, a experiência, a flexibilidade e a visão estrategista, além do otimismo, comprometimento e determinação como demonstra a figura 5 . 


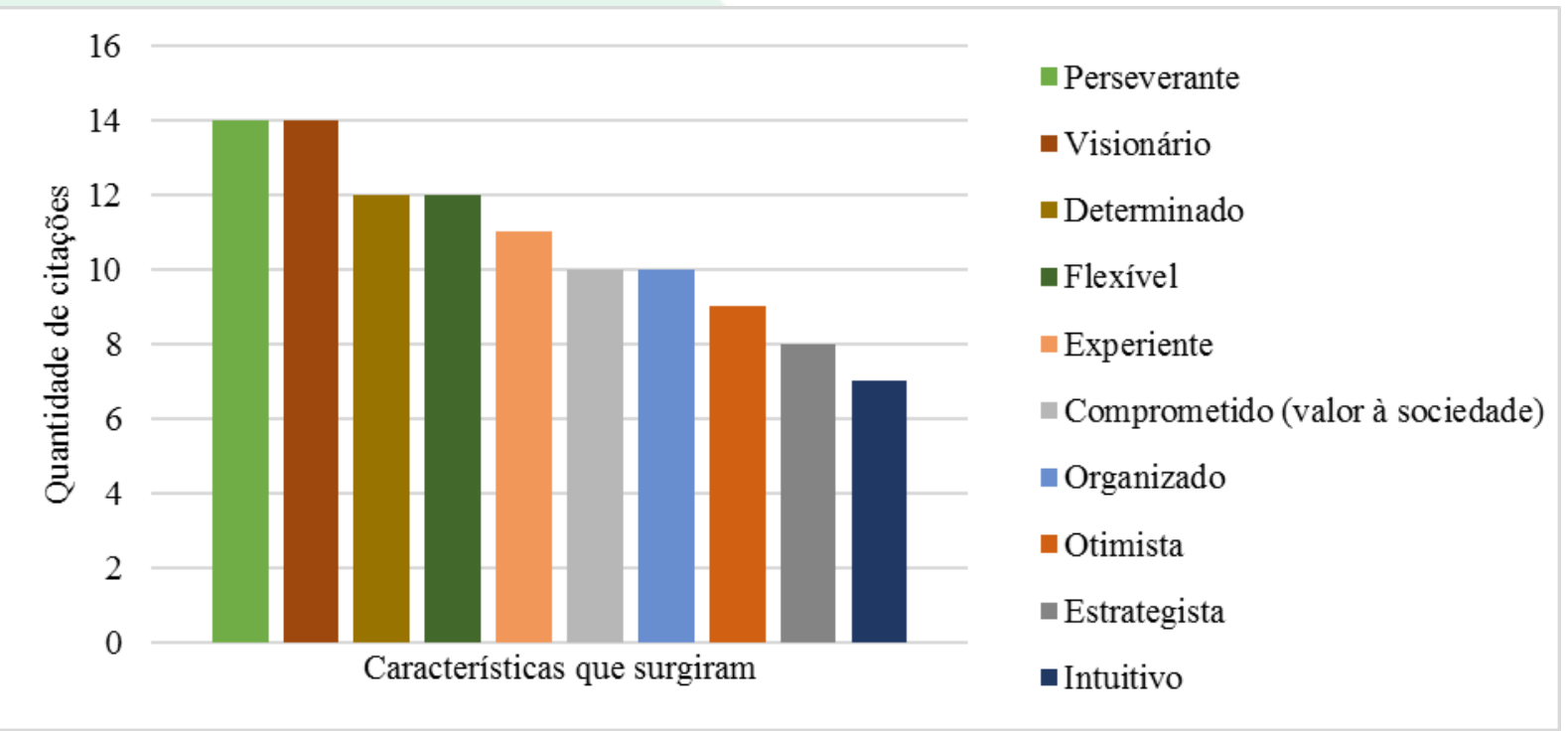

Figura 5 - Principais Características que Surgiram Fonte: Autores, 2014.

Em contrapartida, foi possível verificar o desaparecimento de diversas características como benevolência, desempenho sob pressão, que pode ser explicado pelo fato de que o empreendedor atual precisa ser mais qualificado, conhecer o negócio, possuir certo arrojo e noção de estratégia, tendo menor tolerância ao erro e à benevolência, uma vez que em um mercado mais competitivo, cada vez mais, exige trabalho em equipe, capacidade de comunicação e adaptabilidade a mudanças.

Neste sentido verifica-se que a flexibilidade, organização, comprometimento e a necessidade de uma visão de longo prazo constituem características que reforçam as evidências de que o ambiente externo vem lapidando o perfil do empreendedor contemporâneo.

\section{CONSIDERAÇÕES FINAIS}

Este estudo teve como objetivo analisar a evolução das características do perfil empreendedor, buscando investigar quais são consideradas fundamentais para o perfil empreendedor? Como elas evoluíram ao longo do tempo? Quais características se mantiveram? Quais desapareceram? Quais surgiram? entendendo que investigar a evolução das pesquisas científicas facilita sobremaneira o entendimento deste tema tão instigante.

O horizonte temporal desta pesquisa compreendeu 31 anos, no entanto, partindo da premissa inicial apoiada no estudo de Kuratko e Hodgetts (1995), que abrangeu o período de 1848 e 1982, ou seja, 134 anos, este trabalho consolidou um levantamento dos últimos 165 anos sobre as características empreendedoras que compões o perfil empreendedor.

A presente pesquisa procurou caracterizar e analisar a evolução das características empreendedoras em artigos nacionais e internacionais, publicados entre 1983 e 2014 com a finalidade de tabular as características do perfil empreendedor contemporâneo, e com base nisto verificar as principais mudanças ocorridas.

Como resultados globais da presente pesquisa, podem-se destacar: (i) a considerável elevação do quantitativo de artigos referentes às características empreendedoras, atingindo 26 características citadas em 2007 e, no final do período analisado, 122 características empreendedoras; (ii) o índice de diversidade de autoria, visto que foram considerados 184 autores de 1983 a 2010 e 157 autores de 2011 a 2014, somando 341 autores, mostrando a amplitude e o interesse pelo tema; (iii) o predomínio de características como pró-atividade, inovação, tolerância ao risco e criatividade, demonstrando um posicionamento de diferenciação na atitude empreendedora; (iv) a capacidade de organização, a visão estratégica, o comprometimento e a determinação aparecendo como características de suporte ainda bastante citadas e (v) a constatação de que a globalização e a revolução digital disponibilizaram aos empreendedores e empresas de pequeno porte acesso ao desenvolvimento tecnológico, e esta mudança ambiental vem criando novas oportunidades e promovendo mudanças no perfil do novo profissional.

Foi possível constatar através do presente estudo que as características que compõe o perfil empreendedor contemporâneo são de natureza mais 
objetiva do que subjetiva, mais profissional do que amadora, apontam para um maior foco na inovação e criatividade em busca da diferenciação baseada em maior qualificação e menor peso para fatores como a sorte e os fatores emocionais.

Verificou-se ainda que, assim como o mundo moderno, o perfil do empreendedor contemporâneo está mais dinâmico e complexo, exigindo uma infinidade de características, em maior ou menor nível, de acordo com o tipo de negócio. Constata-se que o estudo que originou esta pesquisa citava características que não resistiram ao peso das mudanças, ao passar dos anos e a evolução do mercado. Por outro lado, algumas características além de se manterem presentes, firmaram-se como fundamentais para o perfil empreendedor contemporâneo, evidenciando a mudança constante em busca de adaptação.

A principal revelação da pesquisa aponta para um perfil empreendedor muito mais relacional, baseado em competências interpessoais e sociais e focado nas demandas do ambiente externo do que o perfil auto centrado, soberano, autônomo e independente do empreendedor da primeira fase do século XX.

Por fim, acredita-se que as maiores contribuições deste trabalho estão na complementação à pesquisa de Kuratko e Hodgetts (1995), por meio da agregação bibliométrica das características do perfil empreendedor consolidando a evolução de todo o período de 1848 até 2014.

Como sugestão para trabalhos futuros pode-se destacar: (i) ampliar o escopo dos meios de publicação, contemplando todos os anais de eventos e periódicos classificados como 'A' no Sistema Qualis/CAPES, (ii) inserir como palavras-chaves competências, habilidades e atitudes empreendedoras e (iii) realizar pesquisa semelhantes em outros países emergentes e comparar os resultados.

\section{REFERÊNCIAS}

Bertalanffy, L. V. (1976). Teoria general de los sistemas: Fundamentos, desarrollo, aplicaciones. Ciudad de Mexico. FCE.

Bolton, B., \& Thompson, J. (2000). Entrepreneurs talent, temperament, technique. Oxford: butterworth Heinemann.

Carland, J. W., Carland, J. A., \& Hoy, F. S. (1998). Who is an entrepreneur? Is a question worth asking? American journal of small business, pp. 3339.

Carvalho, R. S., Zerbini, T., \& Abbad, G. S. (2005). Competências empreendedoras de pequenos empresários: construção e validação de uma escala. In: Souza, E. C. L., Guimarães, T. A. Empreendedorismo além do plano de negócio. São Paulo: Atlas, pp. 217-240.

Cordeiro, A. T., \& Paiva Jr, F. G. (2003). Empreendedorismo e o espírito empreendedor: uma evolução dos estudos na produção acadêmica brasileira. Anais do Encontro Nacional da Associação Nacional de Pós-Graduação e Pesquisa em Administração, Atibaia, SP, Brasil.

Cunha, R. D. A. N. (2004). A Universidade na formação de empreendedores: a percepção prática dos alunos de graduação. Anais do Encontro Nacional da Associação Nacional de PósGraduação e Pesquisa em Administração, Curitiba, PR, Brasil.

Degen, R. (1989). O empreendedor: fundamentos da iniciativa empresarial. São Paulo: MacGraw-Hill.

Dolabela, F. (1999). Oficina do Empreendedor. 1. ed. São Paulo: Cultura Editores Associados.

Dolabela, F. C. (2002). O segredo de Luísa: uma idéia, uma paixão e um plano de negócios: como nasce o empreendedor e se cria uma empresa. 13. São Paulo: Cultura.

Dornelas, J. C. A. (2001). Empreendedorismo, transformando idéias em negócios. São Paulo: Campus.

Drucker, P. F. (1987). Inovação e espírito empreendedor. São Paulo: Pioneira.

Eckert, A., Olea, P. M., Dorion, E. C. E., Mecca, M. S., \& Eckert, M. G. (2013). O perfil empreendedor na graduação: um estudo comparativo entre ingressantes e concluintes. Revista Pensamento Contemporâneo em Administração, 7(2), 61-76.

Filardi, Fernando; Santos, Sílvio Aparecido dos, Oliva; Fábio Lotti, Grisi, Celso Cláudio de Hildebrand \& Lima, Afonso Carneiro. (2012). Análise quantitativa sobre a mortalidade precoce de micro e pequenas empresas da cidade de São Paulo. Revista Gestão e Produção, São Carlos, v. 19, n. 4, p. 811823.

Filardi, Fernando; Silveira, Flavio de Amorim; Capra Luciene Pinheiro; Pereira, Luciano dos Santos; Abreu, Michele Amaral dos Santos Silva. (2011). Desde os Primórdios até hoje em dia será que o Empreendedor ainda faz o que Schumpeter dizia? Evolução das Características Empreendedoras de 
1983 a 2010. DataGramaZero, v.12 n.6 dez11, pp. 01-18.

Filion, L. J. (1999). Empreendedorismo: empreendedores e proprietários-gerentes de pequenos negócios. RAUSP, São Paulo v.34, n.2, abril/junho, pp.05-28.

Gatewood, E. J., \& Shaver, K. G. (2002). Entrepreneurial expectancy, task effort and performance. Entrepreneurship theory and practice.

Gil, A. C. (1999). Como elaborar projetos de pesquisa. São Paulo: Atlas.

Gomes, E. S. F., Forte, J. A. P., Melo, G. H. O., \& Fontenele, R. E. S. (2008). Preditores do perfil empreendedor dos discentes dos cursos de administração. Anais do Encontro Nacional da Associação Nacional de Pós-Graduação e Pesquisa em Administração, Rio de Janeiro, Brasil.

Greatti, L. (2004). O uso do plano de negócios como instrumento de análise comparativa das trajetórias de sucesso e de fracasso empresarial. Anais do Encontro Nacional da Associação Nacional de PósGraduação e Pesquisa em Administração, Curitiba, PR, Brasil.

Guimarães, L. O. (2002). Empreendedorismo no currículo dos cursos de graduação e pósgraduação em administração: análise da organização didático-pedagógica destas disciplinas em escolas de negócios norte-americanas. Anais do Encontro Nacional da Associação Nacional de PósGraduação e Pesquisa em Administração, Salvador, BA, Brasil.

Hindle, K., \& Cutting, N. (2002). Can applied entrepreneurship education enhance job satisfaction and financial performance? An empirical investigation in the Australian pharmacy profession. Journal of small business management, v.40, n.2.

INEP - Instituto Nacional de Estudos e Pesquisas Educacionais Anísio Teixeira. Disponível em: http://www.inep.gov.br/superior/censosuperior/sino pse/default.asp. <acesso em 29 de novembro de 2010>.

Katz, J. A. (2003). The chronology and intellectual trajectory of American entrepreneurship education 1876-1999. Journal of Business Venturing, v.18, n.2, p.283.
Kirzner, I. M. (1986). Competição e atividade empresarial. Rio de janeiro: Instituto Liberal.

Kuratko, D. F., \& Hodgetts, R. M. (1995). Entrepreneurship: a contemporary approach. The Dryden Press series in management, TX - USA.

Kuratko, D. F. (2004). Entrepreneurship education in the 21 century: from legitimization to leadership. A Colemam Foundation White Paper USASBE National Conference, Jan.

Low, M. B. (2001). The adolescence of entrepreneurship research: specification of purpose. Entrepreneurship theory and practice. v.25, n.4, pp. 17-25. Waco: Verão.

McClelland, D. C. (1961). The achieving society. Princeton: D. Van Nostrand.

McClelland, D. C. (1972). A sociedade competitiva realização e progresso Social. Rio de Janeiro: Expressão e Cultura.

Nascimento, O. Dantas, A., \& Santos, P. (2005). Prospecção do potencial empreendedor: validação de uma proposta metodológica. Anais do Encontro Nacional da Associação Nacional de PósGraduação e Pesquisa em Administração, Brasília, DF, Brasil.

Parker, B. (1996). Evolução e Revolução: da Internacionalização à Globalização. In: Caldas, M., Fachin, R., Fischer, T. Handbook de Estudos Organizacionais - Modelos de Análise e Novas Questões em Estudos Organizacionais. v. 1. São Paulo: Atlas, pp. 398-431.

Perera, L. C. J., Nassif, V. M. J., Negro, A. C. M., Bento, L., Pramio, H. S., \& Ono, L. (2004). Missão: formar empreendedores. Anais do Encontro Nacional da Associação Nacional de PósGraduação e Pesquisa em Administração, Curitiba, PR, Brasil.

Peterman, N. E., \& Kennedy, J. (2003). Enterprise education: Influencing students' perceptions of entrepreneurship. Entrepreneurship Theory and Practice.

Pylro, I. F. C. V. (2002). O Empreendedor de Vitória Um Estudo Exploratório, XXII Simpósio da Gestão da Inovação Tecnológica , Salvador. Anais Eletrônico.

Ramos, S. C., \& Ferreira, J. M. (2004). Levantamento das práticas e conteúdos do ensino de 
empreendedorismo nos cursos de graduação em administração na cidade de Curitiba- PR. Anais do Encontro Nacional da Associação Nacional de PósGraduação e Pesquisa em Administração, Curitiba, PR, Brasil.

Rocha, E. L. C., \& Freitas, A. A. F. (2014). Avaliação do ensino de empreendedorismo entre estudantes universitários por meio do perfil empreendedor. Revista de Administração Contemporânea, 18(4), 465-486.

Salim, S., Nasajon, C., Salim, H., \& Mariano, S. (2004). Administração empreendedora: teoria $e$ prática usando estudos de casos. Rio de Janeiro: Campus.

Sebrae (Serviço Brasileiro de Apoio às Micro e Pequenas Empresas). Sobrevivência das Empresas no Brasil. Disponível em: http://www.sebrae.com.br/Sebrae/Portal\%20Sebrae /Anexos/Sobrevivencia_das_empresas_no_Brasil=2 013.pdf. Acesso em 01 de outubro de 2014.

Segal, G., \& Borgia, D. (2005). The motivation to become an entrepreneur. International journal of entrepreneurial behaviour \& research, v.11, n.1, pp.42-57.

Silva, T., Pereira, M. F., Costa, A. M., \& Hinterlang, C. (2013) Metodologia em voga no campo de empreendedorismo: emprego de métodos quantitativos para o estudo das características inerentes aos empreendedores. Revista Ibero-
Americana de Estratégia - RIAE, v. 12, n. 4, pp. 181-209.

Souza, E. C. L., \& Lopez Jr., G. S. (2005). Atitude empreendedora em proprietários-gerentes de pequenas empresas. Construção de um instrumento de medida - IMAE. Anais do Encontro Nacional da Associação Nacional de Pós-Graduação e Pesquisa em Administração, Brasília, DF, Brasil.

Schmidt, S., \& Bohnenberger, M. C. (2009). Perfil empreendedor e desempenho organizacional. Revista de Administração Contemporânea, 13(3), 450-467.

Schumpeter, J. A. (1950). Capitalism, socialism, and democracy. New York: Harper.

Schumpeter, J.A. (1982). The theory of economic development. Oxford University Press.

Vale, G. M. V., Corrêa, V. S., \& Reis, R. F. D. (2014). Motivações para o empreendedorismo: necessidade versus oportunidade?. Revista de Administração Contemporânea, 18(3), 311-327.

Vergara, S. C. (2009). Projetos e relatórios de pesquisa em Administração. $5^{\text {a }}$ Edição. São Paulo: Atlas.

Vesper, K. H., \& Gartner, W. B. (1997). Measuring progress in entrepreneurship education. Journal of Business Venturing, v.13, n.1, p.403. 